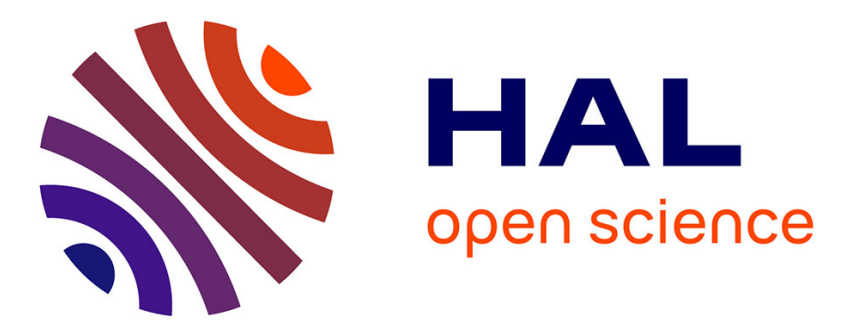

\title{
Characterization of the activation of yttrium-based getter films by electrical measurements and ion-beam analyses
}

Clement Bessouet, Philippe Coste, Johan Moulin, Sylvain Lemettre, Hélène Lecoq, Alain Bosseboeuf, Thierry Sauvage

\section{To cite this version:}

Clement Bessouet, Philippe Coste, Johan Moulin, Sylvain Lemettre, Hélène Lecoq, et al.. Characterization of the activation of yttrium-based getter films by electrical measurements and ion-beam analyses. 2019 Symposium on Design, Test, Integration \& Packaging of MEMS and MOEMS (DTIP), May 2019, Paris, France. 10.1109/DTIP.2019.8752932 . hal-02343431

\section{HAL Id: hal-02343431 \\ https://hal.science/hal-02343431}

Submitted on 2 Nov 2019

HAL is a multi-disciplinary open access archive for the deposit and dissemination of scientific research documents, whether they are published or not. The documents may come from teaching and research institutions in France or abroad, or from public or private research centers.
L'archive ouverte pluridisciplinaire HAL, est destinée au dépôt et à la diffusion de documents scientifiques de niveau recherche, publiés ou non, émanant des établissements d'enseignement et de recherche français ou étrangers, des laboratoires publics ou privés. 
archives-ouvertes

\section{Characterization of the activation of yttrium-based getter films by electrical measurements and ion-beam analyses}

Clement Bessouet, Clément Bessouet, Philippe Coste, Johan Moulin, Sylvain Lemettre, Hélène Lecoq, Alain Bosseboeuf, Thierry Sauvage

\section{To cite this version:}

Clement Bessouet, Clément Bessouet, Philippe Coste, Johan Moulin, Sylvain Lemettre, et al.. Characterization of the activation of yttrium-based getter films by electrical measurements and ion-beam analyses. 2019 Symposium on Design, Test, Integration \& Packaging of MEMS and MOEMS (DTIP), May 2019, Paris, France. pp.1-4, 10.1109/DTIP.2019.8752932 . hal-02343431

\section{HAL Id: hal-02343431 \\ https://hal.archives-ouvertes.fr/hal-02343431}

Submitted on 2 Nov 2019

HAL is a multi-disciplinary open access archive for the deposit and dissemination of scientific research documents, whether they are published or not. The documents may come from teaching and research institutions in France or abroad, or from public or private research centers.
L'archive ouverte pluridisciplinaire HAL, est destinée au dépôt et à la diffusion de documents scientifiques de niveau recherche, publiés ou non, émanant des établissements d'enseignement et de recherche français ou étrangers, des laboratoires publics ou privés. 


\section{Characterization of the activation of yttrium-based getter films by electrical measurements and ion- beam analyses}

\author{
Clément Bessouet \\ Centre de Nanosciences et de \\ Nanotechnologies (C2N), Univ. Paris \\ Sud / CNRS / Univ. Paris Salay \\ 10 boulevard Thomas Gobert, 91120 \\ Palaiseau, France \\ clement.bessouet@u-psud.fr \\ Philippe Coste \\ Centre de Nanosciences et de \\ Nanotechnologies (C2N), Univ. Paris \\ Sud / CNRS / Univ. Paris Salay \\ 10 boulevard Thomas Gobert, 91120 \\ Palaiseau, France \\ philippe.coste@u-psud.fr \\ Johan Moulin \\ Centre de Nanosciences et de \\ Nanotechnologies (C2N), Univ. Paris \\ Sud / CNRS / Univ. Paris Salay \\ 10 boulevard Thomas Gobert, 91120 \\ Palaiseau, France \\ johan.moulin@u-psud.fr
}

\author{
Sylvain Lemettre \\ Centre de Nanosciences et de \\ Nanotechnologies (C2N), Univ. Paris \\ Sud / CNRS / Univ. Paris Salay \\ 10 boulevard Thomas Gobert, 91120 \\ Palaiseau, France \\ sylvain.lemettre@u-psud.fr \\ Hélène Lecoq \\ CNRS-CEMHTI, UPR 3079, site \\ Cyclotron \\ 3 A rue de la Férollerie, 45071 Orlénas \\ Cedex 2, France \\ helene.lecoq@cnrs-orleans.fr
}

\author{
Alain Bosseboeuf \\ Centre de Nanosciences et de \\ Nanotechnologies (C2N), Univ. Paris \\ Sud / CNRS / Univ. Paris Salay \\ 10 boulevard Thomas Gobert, 91120 \\ Palaiseau, France \\ alain.bosseboeuf@u-psud.fr \\ Thierry Sauvage \\ CNRS-CEMHTI, UPR 3079, site \\ Cyclotron \\ 3 A rue de la Férollerie, 45071 Orlénas \\ Cedex 2, France \\ thierry.sauvage@cnrs-orleans.fr
}

\begin{abstract}
Gettering properties of thin films of pure yttrium and yttrium-based alloys have been studied for application to MEMS vacuum packaging at the wafer level. Thin films of $Y$, Zr-Y, Ti-Y and V-Y were co-evaporated under ultra-high vacuum. It is demonstrated that the sheet resistance measured by 4-probes technique before and after activation at $250^{\circ} \mathrm{C}$ gives a good estimation of the oxygen sorption ability determined by NRA. Pure yttrium has been found to be highly reactive after deposition (sheet resistance increases by $40 \%$ after 1 month in air) but poorly efficient in oxygen trapping after activation. Conversely, the sorption ability of $\mathrm{Y}-\mathrm{V}, \mathrm{Y}-\mathrm{Zr}$ and $\mathrm{Y}$-Ti alloys is extremely high and increases with the yttrium content in the film. The bests results for sorption are obtained with Y-V (2.7 $10^{22}$ atom $/ \mathrm{cm}^{3}$ for $\mathrm{Y}_{44} \mathrm{~V}_{56}$ ).
\end{abstract}

Keywords- Getter film, yttrium alloys, oxidation, sheet resistance, in-situ measurement, RBS, NRA

\section{INTRODUCTION}

Vacuum packaging is required for various kinds of microelectromechanical systems (MEMS) such as resonant sensors, bolometers, RF switches and scanners. In most of cases, an internal pressure lower than $10^{-3}$ mbar is mandatory to ensure optimal performances during the MEMS lifetime (10 years). To solve this issue, non-evaporable getter (NEG) thin films are usually integrated in wafer-level packages to trap gases released during outgassing and bonding steps, and to compensate leaks during device lifetime.

NEG thin films are usually based on transition metals because of their high reactivity with gases, and particularly with oxygen after thermal activation. Among them, titanium, vanadium, zirconium or alloys of them eventually doped with rare-earth (RE) additives, are the most common getter films [1].

After deposition, a getter thin film is unable to sorb gases because of its passivation by natural oxide after air exposure. To be able to sorb gases again, it must be activated by thermal annealing under vacuum. This annealing induces a diffusion of oxygen and other surface contaminants into the bulk of the film, which regenerates a metallic and reactive surface.

Titanium and zirconium are getter materials of interest for their high oxygen solubility limit, while vanadium presents a large diffusion length for oxygen [2]. The rare-earth elements facilitate the reduction process of the passivating oxide [3].

NEG films presenting a low activation temperature are characterized by a high density of grain boundaries [2]. The state-of-art in this domain concerns two ternary alloys: Ti-Zr$\mathrm{V}$ and $\mathrm{Zr}-\mathrm{Co}-\mathrm{RE}$. Activation temperatures as low as $200^{\circ} \mathrm{C}-1 \mathrm{~h}$ [2] or $160^{\circ} \mathrm{C}-2 \mathrm{~h}$ [4] for Ti-Zr-V alloy and $200^{\circ} \mathrm{C}-30 \mathrm{~min}$ for $\mathrm{Zr}-\mathrm{Co}-\mathrm{Ce}$ alloy [5] have been demonstrated.

Yttrium has received little attention as a getter material. It is known as an excellent non reversible getter for hydrogen [6], since it can form stable hydrides [7]. It might have also a catalytic effect for the cracking of hydrocarbon gases [8]. If we except argon gas that cannot be sorbed by getter films since it is a noble gas, the main residual gas in a packaged cavity is methane [9-10]. Consequently, Y is expected to be a good candidate as a getter for vacuum packaging. 
In this work the oxygen gettering properties of evaporated thin film of yttrium and yttrium alloyed with zirconium, vanadium or titanium are evaluated. These films were activated during annealing at $250^{\circ} \mathrm{C}$ under argon with traces of oxygen and water vapor. The sorption properties for oxygen were evaluated after annealing by sheet resistance measurements and Nuclear Reaction Analysis (NRA).

\section{EXPERIMENTAL PROCEDURE}

Yttrium and Y-based alloy thin films with variable composition have been elaborated on $100 \mathrm{~mm}$ (100) Si wafers by using a Plassys MEB800S UHV e-beam co-evaporation set-up. Pure yttrium films were deposited at $0.5 \mathrm{~nm} / \mathrm{s}$. Couples of deposition rates were chosen between 0.1 and $0.5 \mathrm{~nm} / \mathrm{s}$ to deposit alloys of Ti-Y, Zr-Y and V-Y with different yttrium content. The thickness of all deposited films was close to 200 $\mathrm{nm}$. Background pressure in the chamber during deposition was in the $10^{-8}$ mbar- $10^{-9}$ mbar range. Hydrogen partial pressure has been monitored during deposition by using residual gas analysis (RGA).

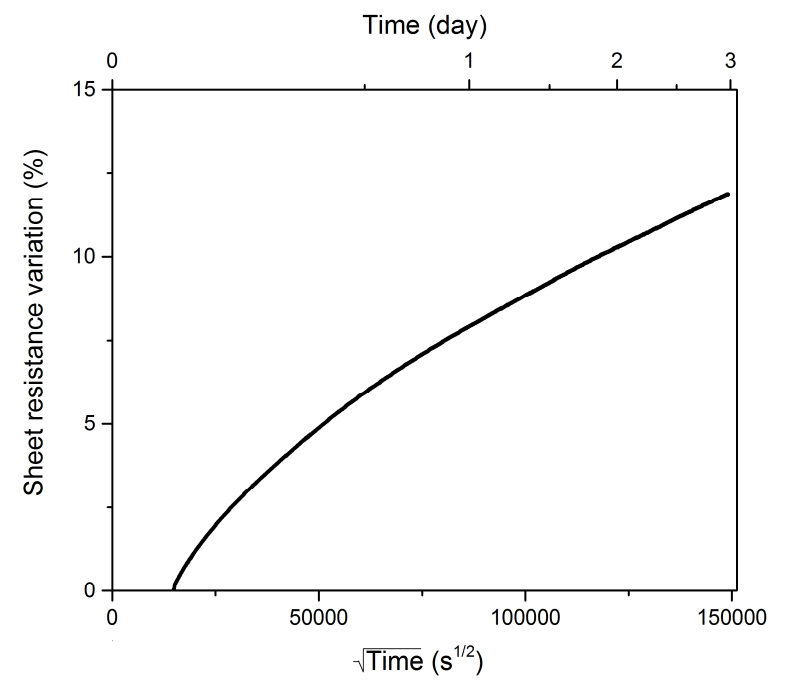

Fig. 1. Sheet resistance variation of a $200 \mathrm{~nm}$-thick yttrium film exposed to ambient air.

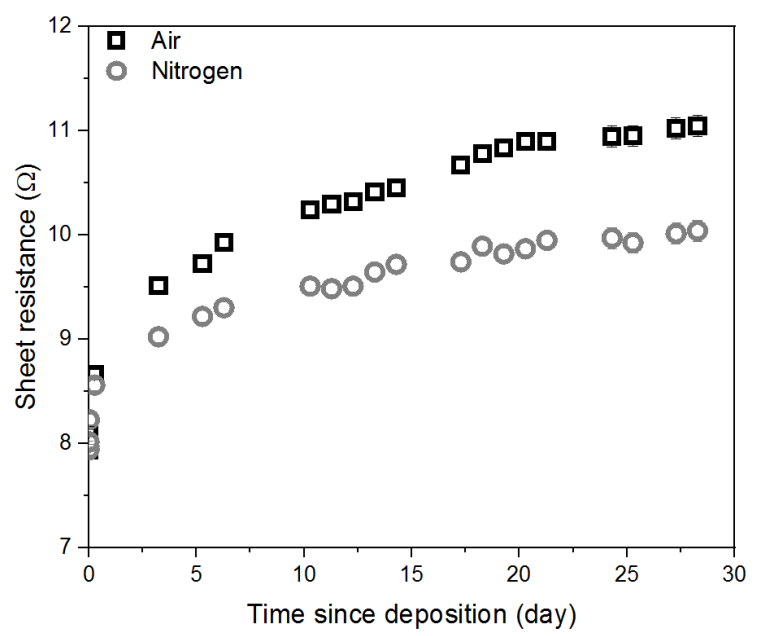

Fig. 2. Comparison between $200 \mathrm{~nm}$-thick yttrium films exposed at ambient air and nitrogen.
Alloy composition of the films were determined by EDS and confirmed by RBS. The thickness of the films was checked by SEM measurement.

The sheet resistance of the films was measured by 4probes electrical measurement just after deposition. This measurement was repeated on a monthly basis since their deposition.

The sorption properties of the films were evaluated after activation at $250^{\circ} \mathrm{C}$ during $75 \mathrm{~min}$ in an oven under argon. Then the oxidation of the samples was estimated by 4-points sheet resistance measurements. The global oxygen content in the films before and after annealing was measured by NRA. Films have been exposed to a deuteron beam at $900 \mathrm{keV}$. Quantification of oxygen is done using the nuclear reaction ${ }^{16} \mathrm{O}\left(\mathrm{d}, \alpha_{0}\right)$ at $166^{\circ}$.

\section{RESULTS AND DISCUSSION}

\section{A. Reactivity at room temperature}

The sheet resistance variations of an yttrium film were measured during 3 days in air from 15 min after its deposition (Fig. 1). The sheet resistance monotonically increases during air exposure. After a transient time of nearly one day, the growth of the sheet resistance is nearly linear with the square root of time. According to Curzon et al [7], the resistivity of a $Y$ film rapidly increases during the first minute of its air exposure, and slowly beyond. However, the measurement duration was limited to only 5 minutes in their experiments.
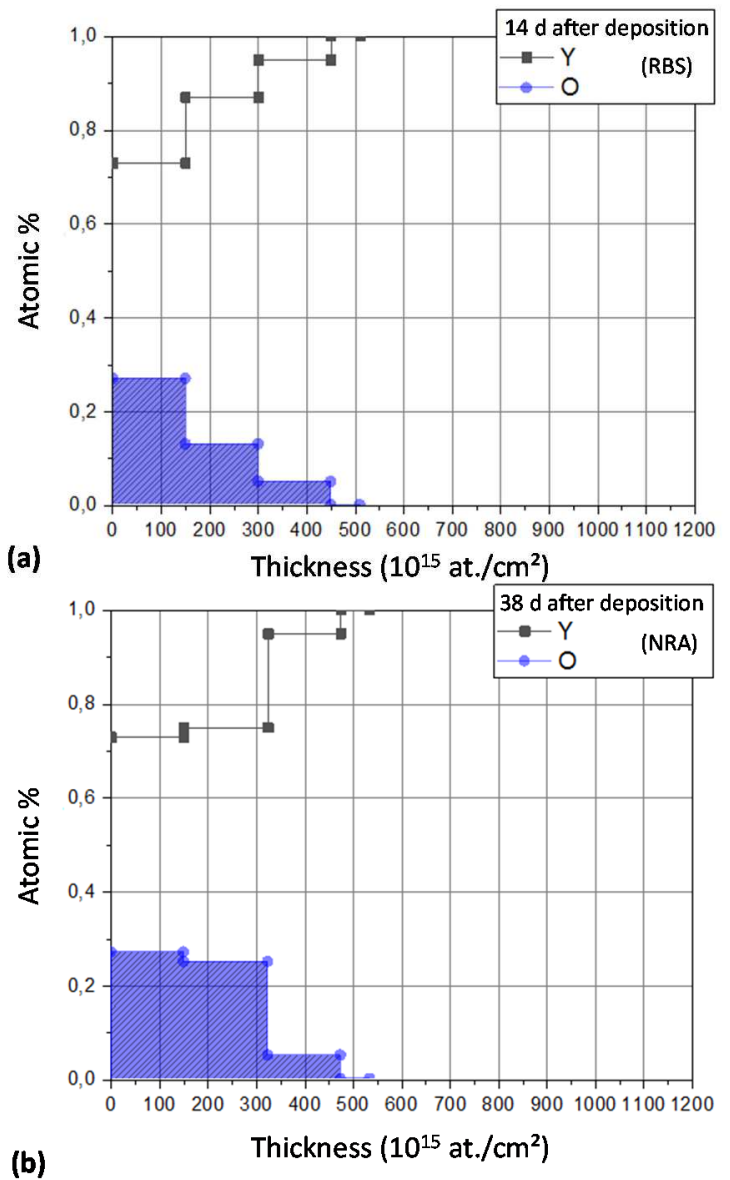

Fig. 3. Oxygen content profile in an yttrium filmafter 14 days of exposure to ambient air deduced by RBS (a) and after 38 days of exposure to ambient air deduced by NRA (b). 
Our experiments show that even after 3 days the yttrium film is not yet efficiently passivated. This would mean that oxygen atoms could be sorbed and diffuse through the surface oxide at room temperature. On a $570 \mathrm{~nm}$-thick yttrium film partly protected by a thin Pd layer and then exposed to ambient air, Huiberts et al [6] measured by RBS a 175 nm-depth penetration of oxygen in agreement with our results. Unfortunately, the duration of air exposure is not mentioned in their work. The sheet resistance of another sample cleaved in the same coated wafer which was stored in a box under nitrogen atmosphere after deposition also monotonically increases for several days, but at a lower rate than in ambient air (Fig. 2). This is consistent with a lower amount of $\mathrm{O}_{2}$ and $\mathrm{H}_{2} \mathrm{O}$ gases in the $\mathrm{N}_{2}$ storage box than in air. The oxygen profile of a Y film stored in ambient air was measured by RBS and NRA at two different times after deposition (Fig. 3). The increasing oxygen content contained in the surface of the film over time confirms the oxidation at ambient air of the Y film.

Sheet resistance measurements of yttrium-based films stored in air are presented in Fig. 4. Conversely to pure yttrium, alloyed films present a nearly constant resistance during the measurement period of almost 3 months. So when yttrium is alloyed with titanium, zirconium or vanadium, the resulting native oxide becomes an efficient passivation layer. This demonstrates a first interesting advantage of Y-alloyed films when compared to pure $Y$ film for their use as getter films: a better reproducibility and stability of their initial state.

\section{B. Activation at $250^{\circ} \mathrm{C}$}

The films were annealed at $250^{\circ} \mathrm{C}$ during 75 min to test their low activation temperature ability. During activation, the oxygen atoms in the surface oxide diffuse into the bulk of the films. We previously demonstrated this activation process for an yttrium film annealed at $250^{\circ} \mathrm{C}$ under high vacuum [11]. In this work, the getter films were exposed to traces of air during activation, so they absorbed $\mathrm{O}_{2}$ and $\mathrm{H}_{2} \mathrm{O}$ molecules. Because of this oxidation, the sheet resistance of the films increased after annealing (Fig. 5). The sheet resistance of the annealed pure yttrium film could not be measured because the film became insulating. For the three alloys, a larger resistance increase was observed than in pure $\mathrm{Ti}, \mathrm{Zr}$ or $\mathrm{V}$ film. The sheet resistance was also found larger for alloy with high yttrium content.

The oxygen content in the annealed films was quantified by NRA (Fig. 6). Results from the NRA were divided by the thickness to obtain doses in at $/ \mathrm{cm}^{3}$. The films with the higher increase in sheet resistance are the ones which have absorbed the more oxygen. This is in agreement with electrical measurements. The maximum oxygen content $\left(2.710^{22}\right.$ at./ $\mathrm{cm}^{3}$ ) was measured for the $\mathrm{Y}_{44} \mathrm{~V}_{56}$ film. Thus $\mathrm{Y}$-alloyed thin films have higher sorption capacities at low temperature for oxygen than pure $\mathrm{Y}$ film. The best oxygen sorption performance is obtained with the V-Y alloy, then Ti-Y and ZrY alloys.

\section{CONCLUSION}

Thin films of Y, Zr-Y, Ti-Y and V-Y were co-evaporated under ultra-high vacuum. Their gettering properties for oxygen were evaluated at $250^{\circ} \mathrm{C}$ by electrical measurements and NRA quantification.

It is evidenced that yttrium film is not stable during its storage in air at room temperature, but alloying yttrium with zirconium, titanium or vanadium increases the film stability.
Alloying also increases the film oxygen gettering ability at low temperature. Among the alloys, the oxygen absorptions

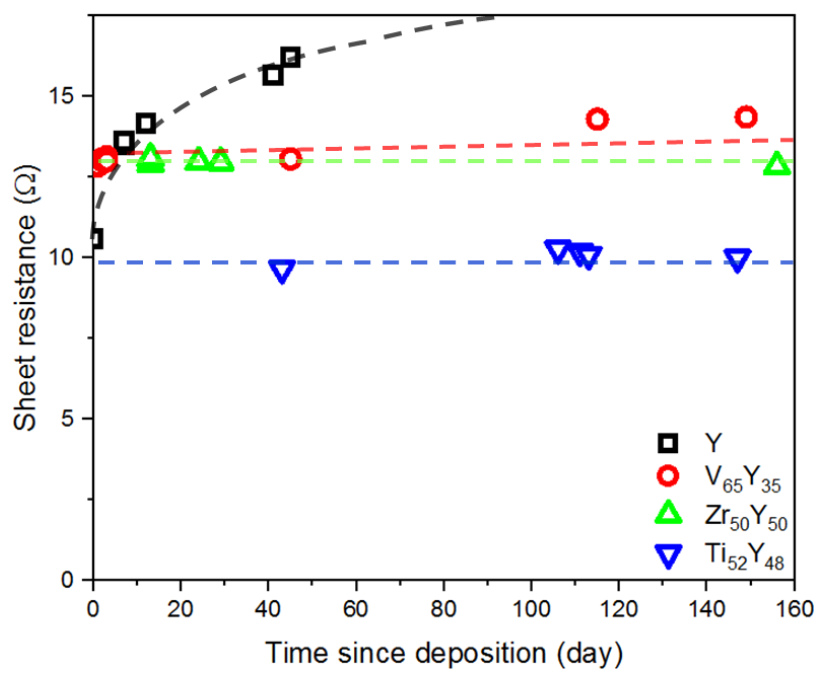

Fig. 4. Sheet resistance evolution of yttrium and Y-alloyed exposed to ambient air.

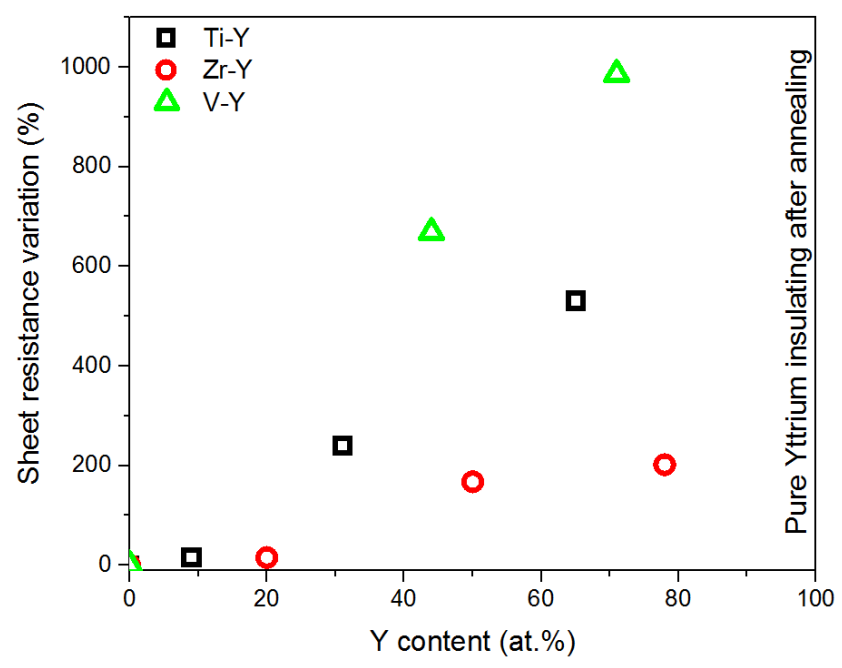

Fig. 5. Sheet resistance variation of yttrium and Y-alloyed films after annealing at $250^{\circ} \mathrm{C}$.

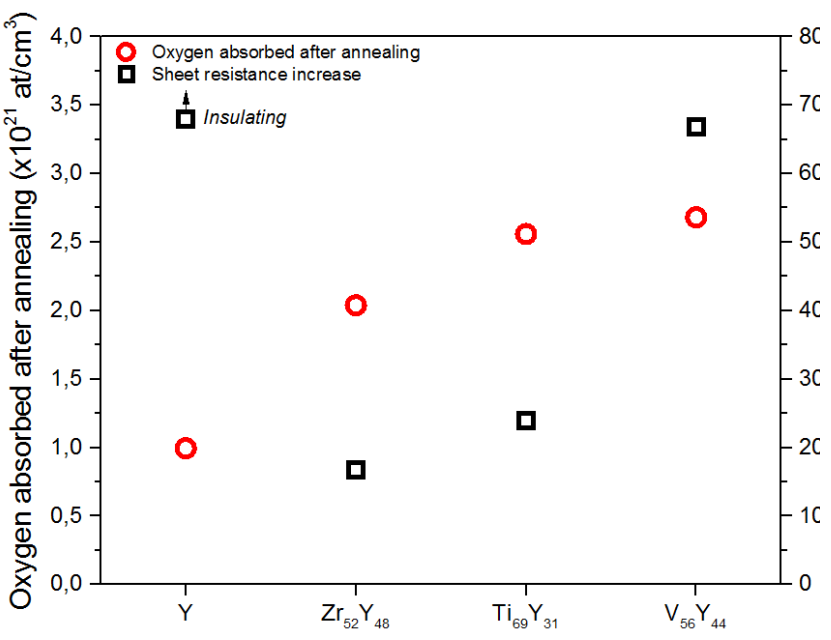

Fig. 6. Quantity of oxygen absorbed and sheet resistance increase of yttrium and alloys after $250^{\circ} \mathrm{C}$ annealing under Ar. 
increase with the yttrium content in the alloy, and the best absorptions were obtained with $\mathrm{V}-\mathrm{Y}$, then with Ti-Y and ZrY.

\section{ACKNOWLEDGMENT}

Film deposition and SEM were performed in the clean rooms facilities of technological center of $\mathrm{C} 2 \mathrm{~N}$ which is partly supported by the Renatech network. This work benefited of a $\mathrm{PhD}$ grant from the French Ministry of Research.

\section{REFERENCES}

[1] R. Ramesham, R. C. Kullberg, "Review of vacuum packaging and maintenance of MEMS and the use of getters therein," Journal of Micro/Nanolithography, MEMS, and MOEMS, vol. 8, no. 3, 031307, Jul-Sep 2009

[2] A. Prodromides, "Non-evaporable getter thin film coatings for vacuum applications," Thesis, Lausanne, EPFL, 2002

[3] Z. Abboud, O. Moutanabbir, "Temperature-Dependent in situ Studies of Volatile Molecule Trapping in Low Temperature-Activated $\mathrm{Zr}$ Alloy-Based Getters," Journal of Physical Chemistry C, vol. 121, no. 6, pp. 3381-3396, 2017

[4] R.K. Sharma et al, "Deposition and in-situ characterization of Ti-Zr-V alloy thin films annealed at different temperatures under ultra-high vacuum conditions," Journal of Alloys and Compounds, vol. 651, pp. 375-381, 5 December 2015
[5] Y. $\mathrm{Xu}$ et al, "ZrCoCe Getter Films for MEMS Vacuum Packaging," Journal of Electronic Materials, vol. 45, no. 1, 2016

[6] J. N. Huiberts at al, "Synthesis of yttriumtrihydride films for ex-situ measurements," Journal of Alloys and Compounds, vol. 239, no. 2, pp. 158-171, 1996

[7] A. E. Curzon, O. Singh, "Thin film studies of yttrium, yttrium hydrides and yttrium oxide", Journal of Physics F: Metal Physics, vol. 8, no. 8, pp. 1619-1625, 1978

[8] Y. Wang et al., "Yttrium-stabilized zirconia-promoted metallic nickel catalysts for the partial oxidation of methane to hydrogen", International Journal of Hydrogen Energy, vol. 34, no. 5, pp. 22522259, 2009

[9] A. Paquet et al, "Influence of ceramic package internal components on the performance of vacuum sealed uncooled bolometric detectors," in Proceedings Volume 8614, Reliability, Packaging, Testing, and Characterization of MOEMS/MEMS and Nanodevices XII, 86140G, 2013

[10] L. Wang et al, "High-Q Wafer Level Package Based on Modified TriLayer Anodic Bonding and High Performance Getter and Its Evaluation for Micro Resonant Pressure Sensor," Sensors, vol. 17, no. 599,2017

[11] C. Bessouet et al, "In situ electrical characterization of YxTiy getter thin films during thermal activation," 29th Micromechanics and Microsystems Europe Workshop, 2018 